\title{
GPPS-CH-2020-154
}

\section{AERODYNAMIC INSTABILITY PREDICTION USING FAST WAVELET SUBJECTED TO TRANSIENT CIRCUMFERENTIAL DISTORTION IN AN AXIAL COMPRESSOR}

\author{
Yang Liu \\ ${ }^{1}$ Institute of Engineering \\ Thermophysics, Chinese \\ Academy of Sciences, \\ ${ }^{2}$ University of Chinese \\ Academy of Sciences \\ liuyang18@iet.cn \\ Beijing, 100190, China \\ Juan Du \\ ${ }^{1}$ Institute of Engineering \\ Thermophysics, Chinese \\ Academy of Sciences, \\ ${ }^{2}$ University of Chinese \\ Academy of Sciences \\ dujuan@iet.cn \\ Beijing, 100190, China
}

\author{
Jichao $\mathrm{Li}^{*}$ \\ ${ }^{1}$ Institute of Engineering \\ Thermophysics, Chinese \\ Academy of Sciences, \\ 2University of Chinese \\ Academy of Sciences \\ lijichao@iet.cn \\ Beijing, 100190, China

Hongwu Zhang
'Institute of Engineering
Thermophysics, Chinese
Academy of Sciences,
'University of Chinese
Academy of Sciences
zhw@iet.cn
Beijing, 100190, China

\author{
Yihan Li \\ ${ }^{1}$ Institute of Engineering \\ Thermophysics, Chinese \\ Academy of Sciences, \\ ${ }^{2}$ University of Chinese \\ Academy of Sciences \\ liyihan@iet.cn \\ Beijing, 100190, China \\ Chaoqun Nie \\ ${ }^{1}$ Institute of Engineering \\ Thermophysics, Chinese \\ Academy of Sciences, \\ 2University of Chinese \\ Academy of Sciences \\ ncq@mail.etp.ac.cn \\ Beijing, 100190, China
}

\begin{abstract}
Fast wavelet tool was employed as an aerodynamic instability prediction tool in an isolated-rotor axial compressor with transient circumferential distortion. The spatial and time-resolved high-frequency pressure transducers were installed circumferentially and along blade chord direction to measure the dynamic pressure signal. In current work, the transient circumferential distortion was generated by a flat-baffle designed as adjustable distortion intensity of $0.90 \%, 4.12 \%$ and $24.75 \%$ with $25 \%, 50 \%$ and $75 \%$ span height to model the distortion generation process in actual compressors. Steady measurement results demonstrated that the stall margin deteriorated by $3.44 \%, 11.14 \%$ and $58.32 \%$ with steady circumferential distortion with $25 \%, 50 \%$ and $75 \%$ span distortion height, respectively. At the moment when transient circumferential distortion was generated, the characteristic line was suddenly transferred to steady distortion characteristic line and stall margin correspondingly deteriorated; and it returned to the characteristic line under uniform inflow condition with wider stall margin when distortion disappeared. Unsteady pressure was measured and analysed using fast wavelet to predict the aerodynamic stability of axial compressor with transient circumferential distortion. Fast wavelet results showed that after the transient circumferential distortion generated, the amplitude of high frequency reconstructed signal (characteristic signal) correspondingly increased, which means the compressor turned into less stable status. When stability enhancement strategy, steady tip air injection, was implemented, the stability was enhanced by $5.21 \%, 4.44 \%, 3.39 \%$ and $8.88 \%$ using $0.41 \%$ design mass flow injection under uniform inflow, steady circumferential distortion with $25 \%, 50 \%$, and $75 \%$ span distortion height, respectively. The amplitude of characteristic signal decreased with injected tip air in all cases. Accordingly, the capability of fast wavelet to predict the stability is verified with circumferential distortion. Therefore, the fast wavelet is a promising aerodynamic stability prediction tool in axial compressor.
\end{abstract}

\section{INTRODUCTION}

Rotating stall and surge are referred to as aerodynamic instabilities in axial compressors which has been studied for past 80 years [1]. The aerodynamic instability prediction in this work has been focused on since the discovery of two types of stall inception, spike [2] and modal wave [3]. The timely detection of spike and modal wave exists slight difference due to the different features of frequency, scale and propagation speed, etc. Currently, the prediction concerning spike is 
expanded from stall inception to pre-stall inception detection via considerable surveillance parameters monitoring the collapse of the blade pressure periodicity, such as auto- [4-5] and cross-correlation [6-7] coefficient, irregularity [8] and parameter Rc [9]. As for the modal wave stall inception, it was initial discovered by McDougall et al. [3] via first harmonic of spatial Fourier analysis in the experiments. Later, Tryfonidis et al. [10] successfully predicted the occurrence of modal wave using travel energy analysis with different warning time in nine different axial compressors, from single to multistage. Based on long-length scale, low frequency characteristic of modal wave and relative research of spike associated with tip leakage flow [11-13], Liu et al. [14] developed fast wavelet analysis to predict the modal wave 110 rotor revolutions prior to stall and the pre-stall inception of spike corresponding the unsteadiness of tip leakage flow in the throttling process. To date, the aerodynamic instability prediction has two main applications, stall warning and active control in axial compressors, and some has been achieved with success in the experimental research [15-16]. However, considering the multi-stage environment and complex inflow condition, it still remains challenge to predict aerodynamic instability and implement active control in actual compressors of aero-engines.

Speaking of one main issue for stall warning, inlet distortion, the axial compressors are often designed to have resistance to inlet distortion. As a type of inlet total pressure distortion, the inlet circumferential distortion has been widely studied as a result of large pitch angle when taking off or the change of flight posture in actual aero-engines. Considerable research investigated the influence of inlet circumferential distortion on performance in subsonic and transonic axial compressor [17-19]. According to previous literature [17-21], it is commonly verified that the inlet distortion can give rise to the performance deterioration in axial compressors. Zhang et al. [17] numerically investigated the influence of circumferential nonuniform inflow on the stability and flow field in a low-speed fans. The results demonstrated that the tip leakage vortex had periodicity as the rotor entered or left the distortion region and the stall occurred when the influence of distortion was not removed in undistorted area, propagating around the annulus. Hah et al. [18] numerically and experimentally investigated the effect of inlet circumferential distortion on performance in a transonic axial compressor to find a strong interaction between unsteady passage shock and boundary layer, resulting in blockage in the passage with increased aerodynamic loss and reduced stall margin. Considering passage or active control, many researchers attempted to stabilize the axial compressor with the inlet circumferential distortion. Dong et al. [19] used novel casing treatment subjected to inlet circumferential distortion to improve the stability by $6-8 \%$ in a low-speed axial compressor. Spakovszky et al. [20] applied steady, unsteady and robust injection using first harmonic of M-G modal as feedback to stabilize the single stage transonic axial compressor by $4 \%, 9 \%$ and $16.4 \%$. Schalkwyk et al. [21] validated the Hynes-Greitzer distorted flow model as prediction to actively stabilize the low-speed three-stage axial compressor by $3.7 \%$ and $40 \%$ with different inlet circumferential distortion. Additionally, the transient inlet distortion of inlet rotating and swirl distortion has been focused on in last decades [22-24]. However, it is still necessary to develop a method to predict the aerodynamic instability more precisely, taking actual transient distortion generation process into consideration.

In current work, the paper is organized as follows. Primarily the previous research concerning rotating stall prediction methods and inlet circumferential distortion is introduced to emphasize the importance of current research. Subsequently the methodology of fast wavelet is briefly presented. The experimental setup and data acquisition system is described in the next chapter. Then the feasibility of fast wavelet is verified to predict the stability under different inflow condition, clean inflow, inlet circumferential distortion and steady injection with inlet circumferential distortion included. Finally, some conclusions are drawn to summarize current work.

\section{METHODOLOGY}

Wavelet has been employed to investigate the aerodynamic instability behaviour by Lin et al. [25] and Liao et al. [26] in axial compressors due to its well capability to analyse temporal-frequency features of instability disturbances. Fast wavelet analysis, also named multiresolution analysis, has been proposed by Mallat [27-28] in 1989. The continuous wavelet analysis and the properties of "Morlet" and "Meyer" wavelet base has been described in detail in literature [25]. Moreover, fast wavelet theory has been fully introduced in literature [14]. The following presents the main equations and parameters according to fast wavelet theory.

$$
\begin{array}{lr}
\text { Scaling function } \psi(x): & \psi(x)=\sqrt{2} \sum_{k \in Z} h_{k} \psi(2 x-k) \cdot \\
\text { Wavelet function } \phi(x): & \phi(x)=\sqrt{2} \sum_{k \in Z} g_{k} \phi(2 x-k) \cdot \\
\text { Low pass filter factor } h_{k}: & h_{k}=\int \psi(x) \overline{\psi_{1, k}(x)} d x=\sqrt{2} \int \psi(x) \overline{\psi(2 x-k)} d x . \\
\text { High pass filter factor } g_{k}: & g_{k}=(-1)^{k} \bar{h}_{1-k} \cdot
\end{array}
$$




$$
f_{j}(x)=\sum_{k \in Z} c_{j k} \psi_{j k}(x)=\sum_{k \in Z} c_{j-1, k} \psi_{j-1, k}(x)+\sum_{k \in Z} d_{j-1, k} \phi_{j-1, k}(x) .
$$

Scaling coefficient $c_{j k}$ :

Wavelet coefficient $d_{j k}$ :

$$
c_{j k}=\left\langle f_{j}, \psi_{j k}\right\rangle \text {. }
$$

$$
d_{j k}=\left\langle f_{j}, \phi_{j k}\right\rangle \text {. }
$$

From equations (1) to (7), the parameters $\mathrm{j}$ and $\mathrm{k}$ represent the time and scale parameters concerning time and frequency domain. The wavelet base employed in current study is Daubechies 3 wavelet with three order of vanishing moment, presented in Figure 1.

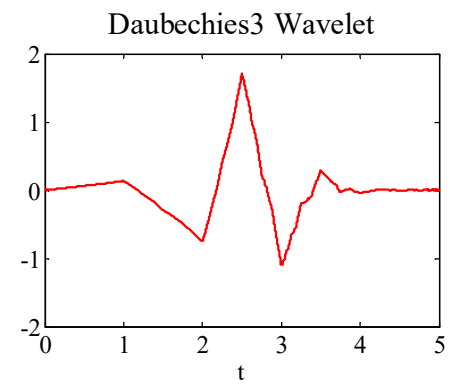

Figure 1 Daubechies3 Wavelet

\section{EXPERIMENTAL SETUP}

The experiments in current study were conducted in an isolated-rotor axial compressor with design rotational speed of $2400 \mathrm{rpm}$ of the advanced gas turbine laboratory, IET. The blade of this compressor is modelled from a high-pressure compressor. The main geometrical and aerodynamic parameters of this compressor are presented in Table 1. The Mach number at tip is about 0.16 . Figure 2 shows the isolated-rotor axial compressor and the inlet circumferential distortion screen where the flat-baffle is inserted to generate different distortion intensity. The flat-baffle height is defined as distortion height variable as $25 \%, 50 \%$ and $75 \%$ blade span height. The transient distortion generation time is about 4 rotor revolutions to release the flat-baffle to the desired position.

Table 1 Detailed Parameters of Isolated-Rotor Axial Compressor

\begin{tabular}{lc}
\hline \multicolumn{1}{c}{ Parameters } & Isolated-Rotor \\
\hline Blade number & 60 \\
Rotor tip stagger angle/ & 39.2 \\
Outer diameter $/ \mathrm{mm}$ & 500 \\
Rotor blade tip chord $/ \mathrm{mm}$ & 36.3 \\
Rotor tip clearance $/ \mathrm{rotor}$ tip chord, \% & 2.6 \\
Hub-to-tip ratio & 0.75 \\
\hline Design rotating speed $/ \mathrm{rad} \cdot \mathrm{min}^{-1}$ & 2400 \\
Design mass flow rate $/ \mathrm{kg} \cdot \mathrm{s}^{-1}$ & 2.9 \\
\hline
\end{tabular}

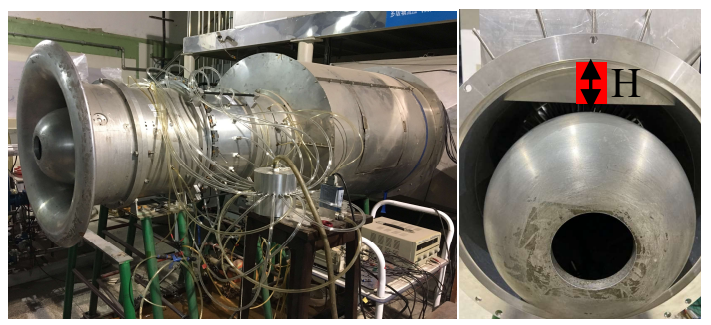

Figure 2 Isolated-Rotor Axial Compressor and Distortion Generator

Figure 3 depicts the data acquisition system of the isolated-rotor axial compressor. Four static pressure taps are mounted uniformly 8 axial chord length $\left(\mathrm{C}_{a x}\right)$ upstream of the rotor in the inlet duct and $4 \mathrm{C}_{a x}$ downstream of the rotor in the exit duct to measure the inlet and outlet static pressure to calculate the flow and pressure rise coefficient. Five five-hole comb total pressure probes are installed every 72 degrees around the annulus to calculate the distortion intensity after the distortion is generated. Twenty-six transducers (Kulite XCS-190) with high-response frequency of 150k Hz are spaced 
along the axial chord direction and circumferentially to measure the unsteady pressure. Eight are circumferentially arranged at $15.08 \% \mathrm{C}_{a x}$ to describe the development and propagation of the initial stall inception. Four rows of twenty-two transducers (six at first and third row; five at second and forth row) are mounted from $9.16 \%$ upstream of the leading edge (LE) to $112.5 \% \mathrm{C}_{a x}$ downstream of the trailing edge (TE) or $88.26 \% \mathrm{C}_{a x}$. The sampling frequencies of data acquisition are above $40 \mathrm{k} \mathrm{Hz}$, which is much higher than the blade passing frequency (BPF) of approximate $2.4 \mathrm{k} \mathrm{Hz}$ to satisfy the requirement of dynamic pressure measurement. In the experiments, the throttle valve is controlled by a DC motor, gradually continuously closing to approach the stability limit.

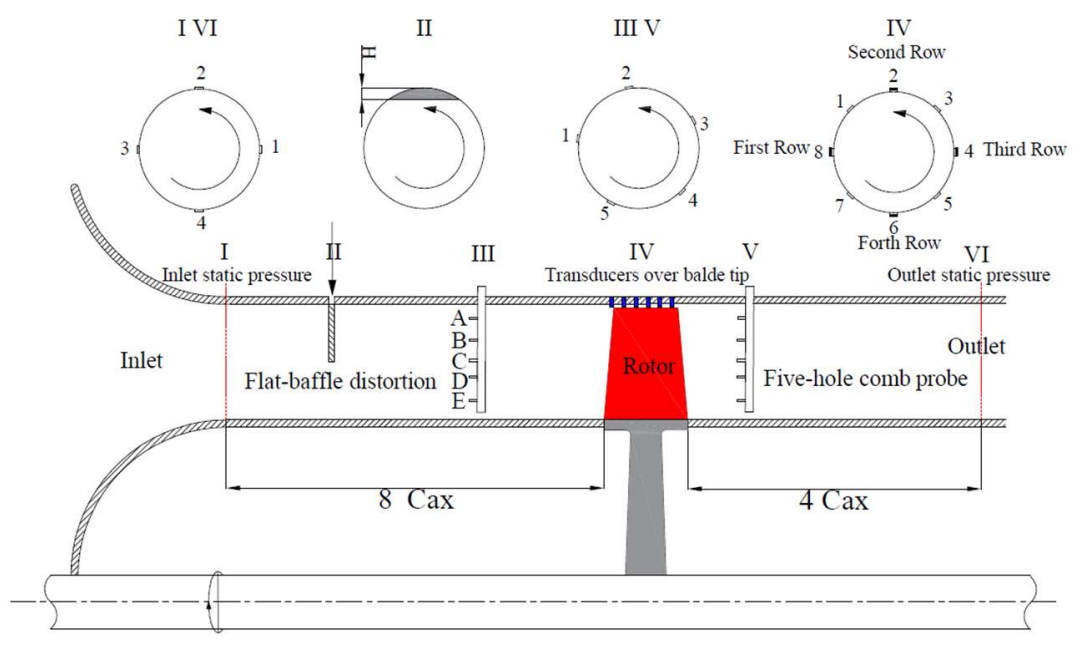

Figure 3 Data Acquisition System

\section{RESULTS AND DISCUSSION}

\section{Validation under Uniform Inflow}

The performance of this axial compressor is dependent on the flow and static-to-total pressure rise coefficient, shown in Figure 4. The flow and static-to-total pressure rise coefficient are defined as follows:

$$
\begin{array}{lc}
\text { Flow Coefficient } \Phi: & \Phi=\frac{V_{x, \text { inlet }}}{U_{\text {mid }}} . \\
\text { Pressure Rise Coefficient } \Psi: & \Psi=\frac{2\left(P_{s, \text { exit }}-P_{t, \text { inlet }}\right)}{\rho U_{\text {mid }}^{2}} . \\
\text { Inlet Average Velocity } V_{x, \text { inlet }}: & V_{x, \text { inlet }}=\sqrt{\frac{2\left(P_{t, \text { inlet }}-P_{s, \text { inlet }}\right)}{\rho} .}
\end{array}
$$

where $\rho$ denotes atmosphere air density and $U_{\text {mid }}$ represents tangential velocity at the mid-span. The subscript $\mathrm{t}$ represents the total pressure and subscript s denotes the static pressure. The Mach number is lower than 0.16 so that the flow can be regarded as incompressible and equation (10) is validated. In the experiments, the axial compressor is continuously throttled into stall. The flow and static-to-total pressure rise coefficient are 0.404 and 0.385 at the stall point. The characteristic lines of four tests basically coincide to demonstrate the repeatability of experiments and measurement.

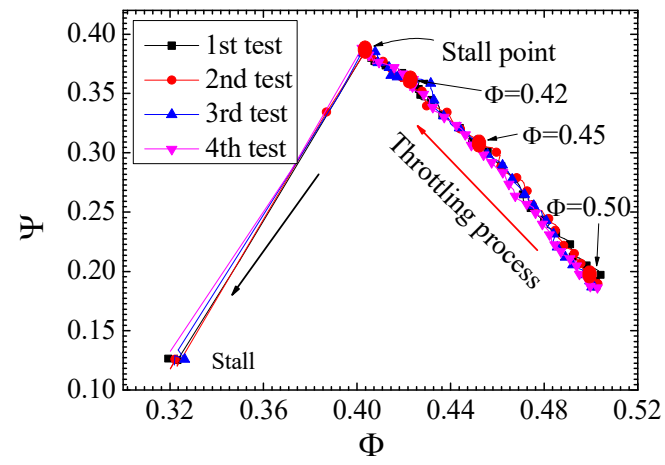




\section{Figure 4 Performance Lines of Isolated-Rotor Axial Compressor}

Figure 5 depicts the development and circumferential propagation of stall inception. The abscissa is the time in the unit of rotor revolution and the ordinate is circumferential location. The grey is the original unsteady pressure measured by dynamic transducers; and the red is the low-pass filtered original pressure signal with $200 \mathrm{~Hz}$ cut-off frequency. The initial stall inception is detected via $\mathrm{CH} 2$ at 454.2 rotor revolution, and it then propagates at the speed of $66.7 \%$ rotational speed. After low-pass filter, the spike emerges approximately 4 rotor revolution time before stall, which is not sufficient for stall warning or active control in axial compressors. Hence, the fast wavelet analysis is adopted to detect the pre-stall inception as described in literature [14].

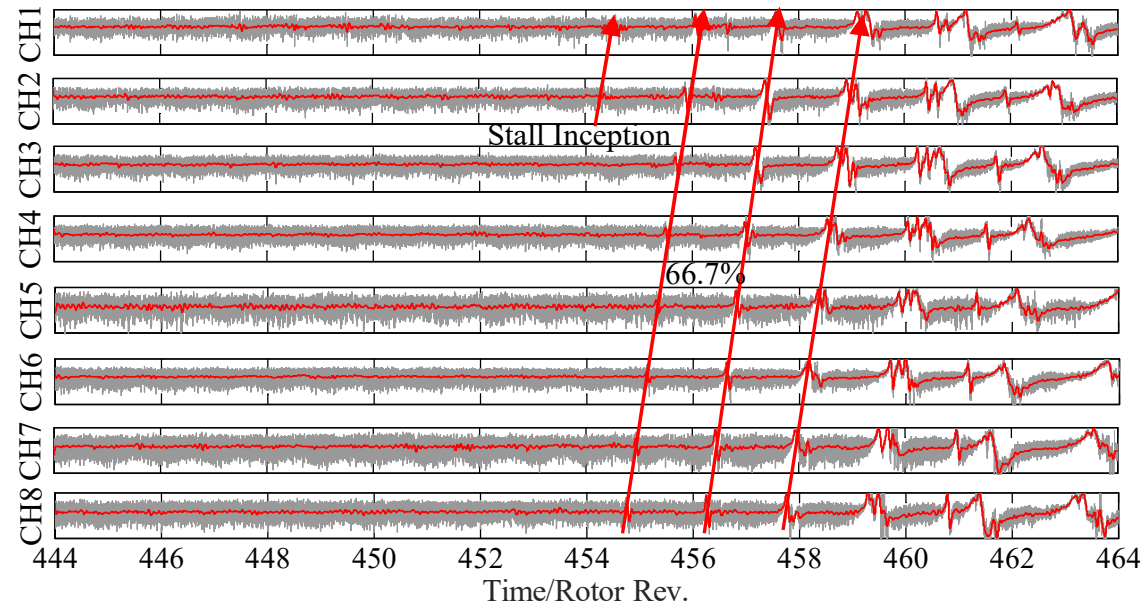

Figure 5 Stall Route at $\mathbf{1 5 . 0 8 \%} \mathrm{C}_{a x}$ under Uniform Inflow

Figure 6 depicts the fast wavelet analysis results in the throttling process at $15.08 \% \mathrm{C}_{a x}$ of $\mathrm{CH} 2$. Three flow coefficients are selected to model the throttling process. The abscissa is the time in the unit of rotor revolution and the ordinate is the sixth order high frequency reconstructed signal (characteristic signal) of original unsteady pressure in unit of Pa. The amplitude of characteristic signal gradually increases from the large flow coefficient $(\Phi=0.50)$ to the near stall point $(\Phi=0.42)$ as the throttle valve is closing. Hence, the characteristic signal can be regarded as pre-stall inception for spike to monitor the stable status of the compressor. In addition, the frequency of characteristic signal is located at the 0.2-0.8 BPF associated with the unsteady tip leakage flow (UTLF) from the previous analysis in literature [11-14].

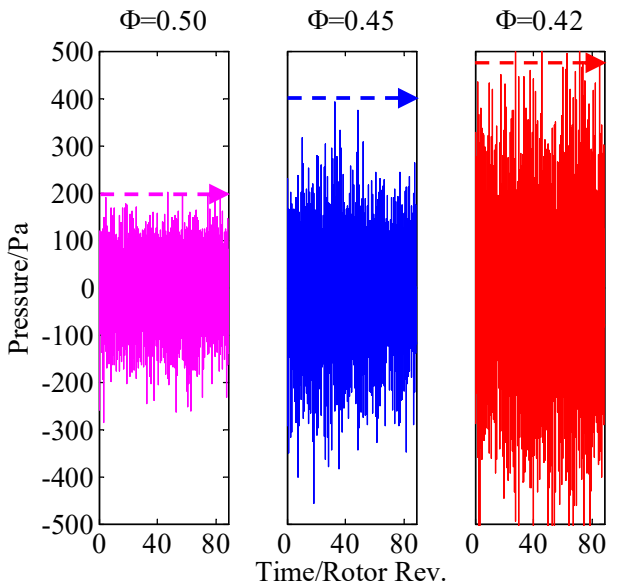

Figure 6 Pre-stall Inception at $\mathbf{1 5 . 0 8 \%} \mathrm{C}_{a x}$ under Uniform Inflow

\section{Validation with Inlet Circumferential Distortion}

When the compressor suffers from complex inflow condition, its performance undergoes deterioration dependent on the distortion intensity, which is a parameter to evaluate the circumferential unevenness triggered by distortion. In this study, the commonly accepted distortion intensity definition DC (60) is adopted as follows:

$$
D C(60)=\frac{\bar{P}_{t, \text { distortion }, 360^{\circ}}-\bar{P}_{t, \text { worst } 60^{\circ}}}{P_{t, \text { inlet }}-P_{s, \text { inlet }}} .
$$


where $\bar{P}_{t, \text { distortion } 360^{\circ}}$ represents the average total pressure in the distortion section measured by five five-hole comb total pressure probes; $\bar{P}_{t, \text { worst } 60^{\circ}}$ represents the average total pressure within the worst 60 degree sector (low pressure region); $P_{t, \text { inlet }}$ denotes the total pressure in the inlet duct; and $P_{s, \text { inlet }}$ is on behalf of the static pressure in the inlet duct measured by four uniformly arranged sensors. In current study, the transient circumferential distortion occurs when the flat-baffle falls down from the casing to model the actual distortion generation process. The distortion height of flat-baffle is variable as $25 \%, 50 \%$ and $75 \%$ blade span height, respectively. The distortion intensity of $25 \%, 50 \%$ and $75 \%$ span distortion height are $0.90 \%, 4.12 \%$ and $24.75 \%$, respectively. One can be noted that the distortion intensity increases as the increase depth of the flat-baffle.

Figure 7 presents the performance lines with transient or steady inlet circumferential distortion with different distortion intensity. The abscissa of flow coefficient and the ordinate of pressure rise coefficient are defined from above analysis. The black line is the characteristic line under uniform inflow in subfigures (a), (b) and (c); the red circle represents the characteristic lines with steady circumferential distortion; and the blue circle represents the characteristic lines with transient circumferential distortion. With steady distortion with variable intensity, the stability of compressor is adversely affected. To evaluate the adverse effect of steady distortion, dimensionless parameters of stall margin (SM) and stall margin variation (SMV) are defined in equations (12) and (13):

$$
\begin{gathered}
S M=\left(\frac{\Psi_{s} / \Phi_{s}}{\Psi_{d} / \Phi_{d}}-1\right) \times 100 \% . \\
S M V=S M_{\text {distortion }}-S M_{\text {uniform }} \times 100 \% .
\end{gathered}
$$

where the subscript $\mathrm{s}$ and $\mathrm{d}$ denote the stall point and design point, respectively. From the aerodynamic parameter of design mass flow rate in Table 1, the flow and pressure rise coefficient at the design point can be calculated, 0.465 and 0.278 . From the subfigures (a) to (c) in Figure 7, the flow and pressure rise coefficient under different distortion intensity is shown in Table 2. As it can be seen from Table 2, the adverse influence of $25 \%$ span distortion height is slight (-3.44\%); under $50 \%$ span distortion height the stability margin decreases by $11.14 \%$; and the distortion with $75 \%$ span considerably deteriorates the stability by $58.32 \%$. As for transient circumferential distortion, the characteristic line transfers from uniform inflow line into steady distortion line driven by distortion. When the distortion disappears, the characteristic line returns to uniform inflow line. Moreover, when the distortion is generated at the steady distortion stall point $(\Phi=0.45)$ in subfigure (c) of Figure 7, the compressor immediately enters deep stall. Hence, it is of the same significance to study the adverse effect of steady distortion on compressor compared to the actual transient distortion process.

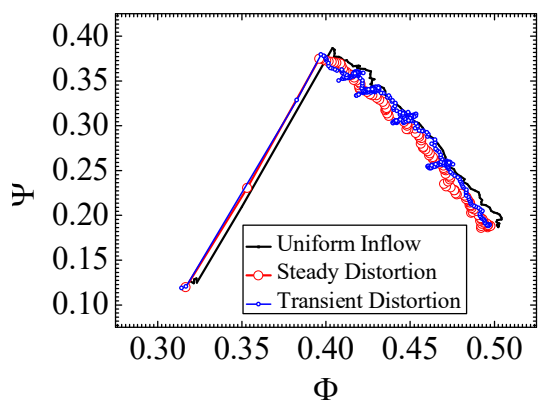

(a) Distortion with $25 \%$ blade span

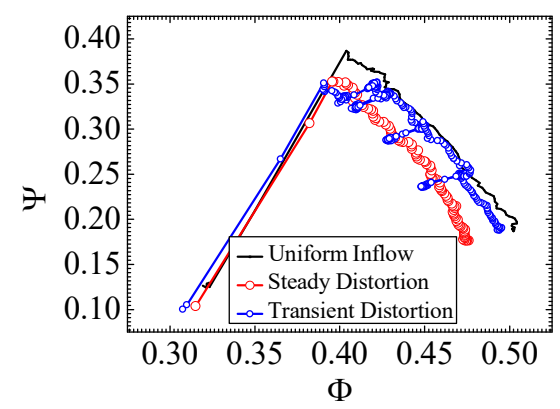

(b) Distortion with $50 \%$ blade span

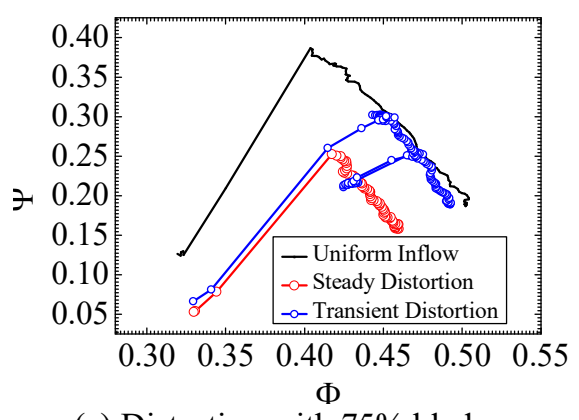

(c) Distortion with $75 \%$ blade span

Figure 7 Performance lines with Distortion

Table 2 SMV with Different Distortion Intensity

\begin{tabular}{|c|c|c|c|c|}
\hline & Uniform Inflow & $\begin{array}{c}\text { Distortion with 25\% } \\
\text { Span }\end{array}$ & $\begin{array}{c}\text { Distortion with 50\% } \\
\text { Span }\end{array}$ & $\begin{array}{c}\text { Distortion with 75\% } \\
\text { Span }\end{array}$ \\
\hline Dat Stall Point & 0.404 & 0.400 & 0.396 & 0.417 \\
\hline$\Psi$ at Stall Point & 0.385 & 0.373 & 0.351 & 0.252 \\
\hline SMV & 0 & $-3.44 \%$ & $-11.14 \%$ & $-58.32 \%$ \\
\hline
\end{tabular}

Based on previous validation under uniform inflow condition, the unsteady pressure is analysed via fast wavelet analysis to investigate the reliability of characteristic signal to monitor the stability status with circumferential distortion. Figure 8 depicts the characteristic signals at $15.08 \% \mathrm{C}_{a x}$ of $\mathrm{CH} 2$ with different distortion condition. The abscissa is time in the unit of rotor revolution and the ordinate is the amplitude of characteristic signal in unit of Pa. Under uniform inflow, the characteristic signal increases in the continuous throttling process, consistent with Figure 6. Compared to uniform inflow condition, the characteristic signal increases slightly with transient circumferential distortion with $25 \%$ span distortion height. The influence of transient process is not obvious, which coincides the slight adverse effect on stability margin. As the distortion intensity enhanced to 50\% span distortion height, the characteristic signal suffers from sudden increase accompanied by the distortion generation. Moreover, the characteristic signal decreases to uniform inflow level 
when the circumferential distortion disappears. The similar phenomenon with strongest distortion can be observed as well. In addition, the amplitude of characteristic signal correspondingly increases as the distortion becomes stronger. From above analysis, the characteristic signal can timely reflect the adverse effect of distortion on the compressor stability.
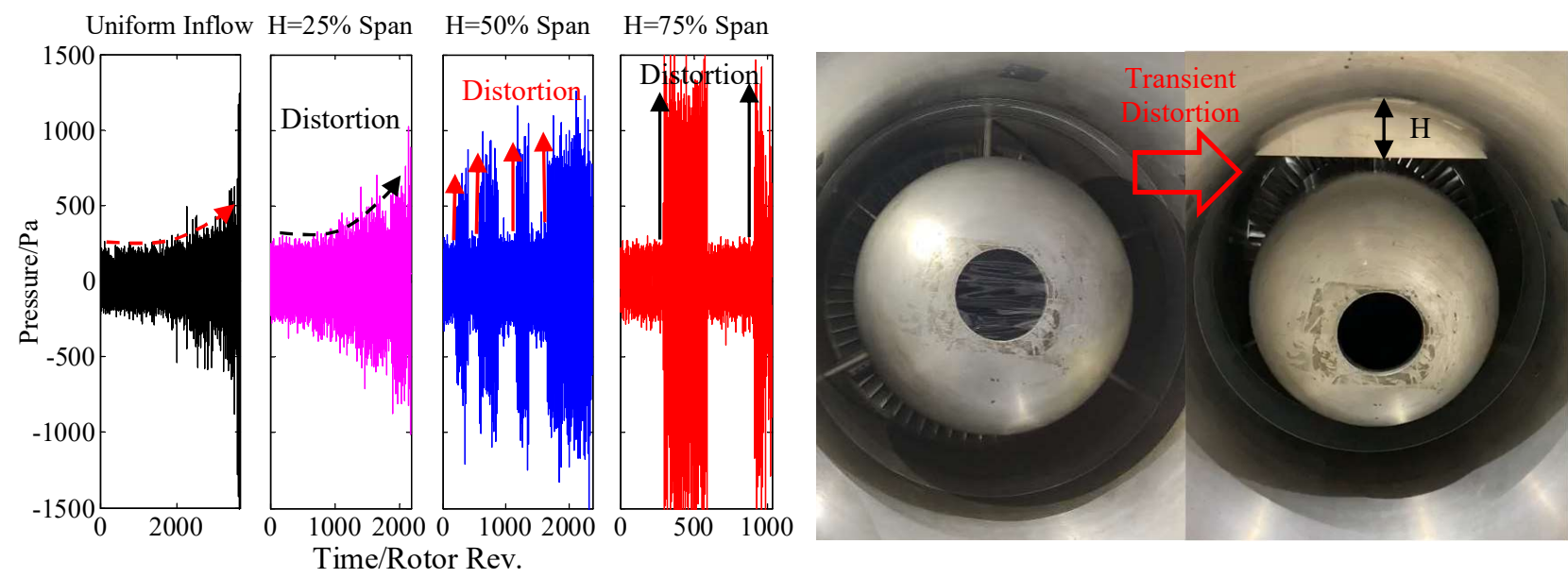

Figure 8 Characteristic Signal at $15.08 \% \mathrm{C}_{a x}$ under Transient Distortion

\section{Validation with Steady Injection under Inlet Circumferential Distortion}

The tip air injection is regarded as a stability enhancement strategy to improve the stall margin in axial compressors. Eight Conada injectors [7] are spaced $0.6 \% \mathrm{C}_{a x}$ upstream of the rotor to implement the steady tip air injection. The injected air mass is $0.41 \%$ design mass flow of the compressor. Figure 9 represents the characteristic lines with different distortion and injection cases. The abscissa of flow coefficient and the ordinate of pressure rise coefficient are defined in equations (8-9). Case A represents the uniform inflow condition; Case C, E and G represent the steady distortion condition; and Case $\mathrm{B}, \mathrm{D}, \mathrm{F}$ and $\mathrm{H}$ represent the steady injection under uniform inflow, steady distortion with $0.90 \%, 4.12 \%$ and $24.75 \%$ distortion intensity. The stall margin is improved by steady tip air injection in all cases. The parameter SMI is presented in Table 3 according to equation (14). The steady tip air injection improves the stall margin by 5.21\%, 4.44\%, 3.39\% and $8.88 \%$ under uniform inflow, distortion with $0.90 \%, 4.12 \%$ and $24.75 \%$ distortion intensity, respectively.

$$
S M I=\frac{\Phi_{\text {noinjection }}}{\Phi_{\text {injection }}}-1 \times 100 \% \text {. }
$$

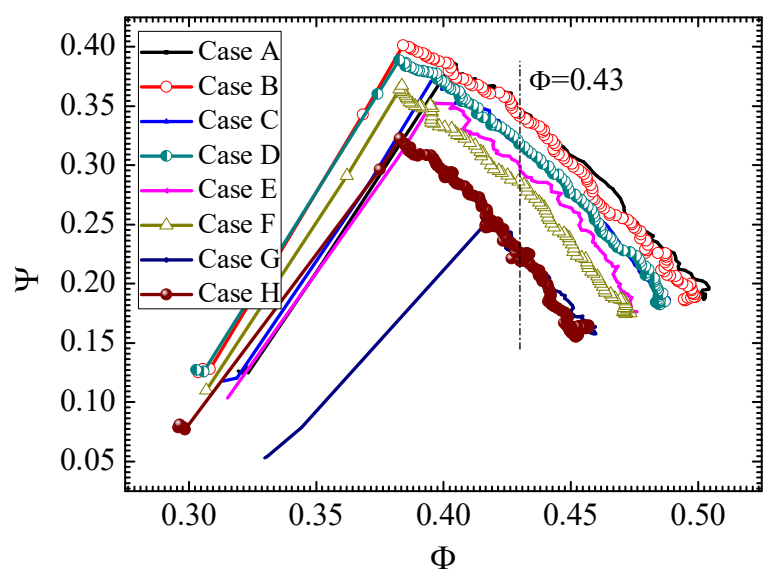

Figure 9 Performance lines with Steady Injection with Distortion

Table 3 SMV with Steady Tip Air Injection with Different Distortion Intensity

\begin{tabular}{|c|c|c|c|c|}
\hline & $\begin{array}{c}\text { Injection under } \\
\text { Uniform Inflow }\end{array}$ & $\begin{array}{c}\text { Injection with 25\% } \\
\text { Span Distortion }\end{array}$ & $\begin{array}{c}\text { Injection with 50\% } \\
\text { Span Distortion }\end{array}$ & $\begin{array}{c}\text { Injection with 75\% } \\
\text { Span Distortion }\end{array}$ \\
\hline Tat Stall Point & 0.384 & 0.383 & 0.383 & 0.383 \\
\hline$\Psi$ at Stall Point & 0.401 & 0.388 & 0.364 & 0.323 \\
\hline SMI & $5.21 \%$ & $4.44 \%$ & $3.39 \%$ & $8.88 \%$ \\
\hline
\end{tabular}

To investigate whether the characteristic signal can reflect the stability enhancement of steady tip air injection, the fast wavelet analysis is adopted to analyse the unsteady pressure. The characteristic signals at $15.08 \% \mathrm{C}_{a x}$ of $\mathrm{CH} 2$ with or 
without steady tip air injection under different inflow conditions $(\Phi=0.43)$ are presented in Figure 10 . The abscissa and the ordinate are the same as in Figure 8. In all cases, the amplitude of characteristic signal correspondingly decreases with the steady tip air injection compared to no injection condition. In addition, the decrease of characteristic signal amplitude depends on the stability margin improvement, which means the characteristic can demonstrate the stable status of axial compressor and the stall margin improvement level. Accordingly, the characteristic signal analysed via fast wavelet is a promising aerodynamic stability prediction method for stall warning and active control in axial compressors.
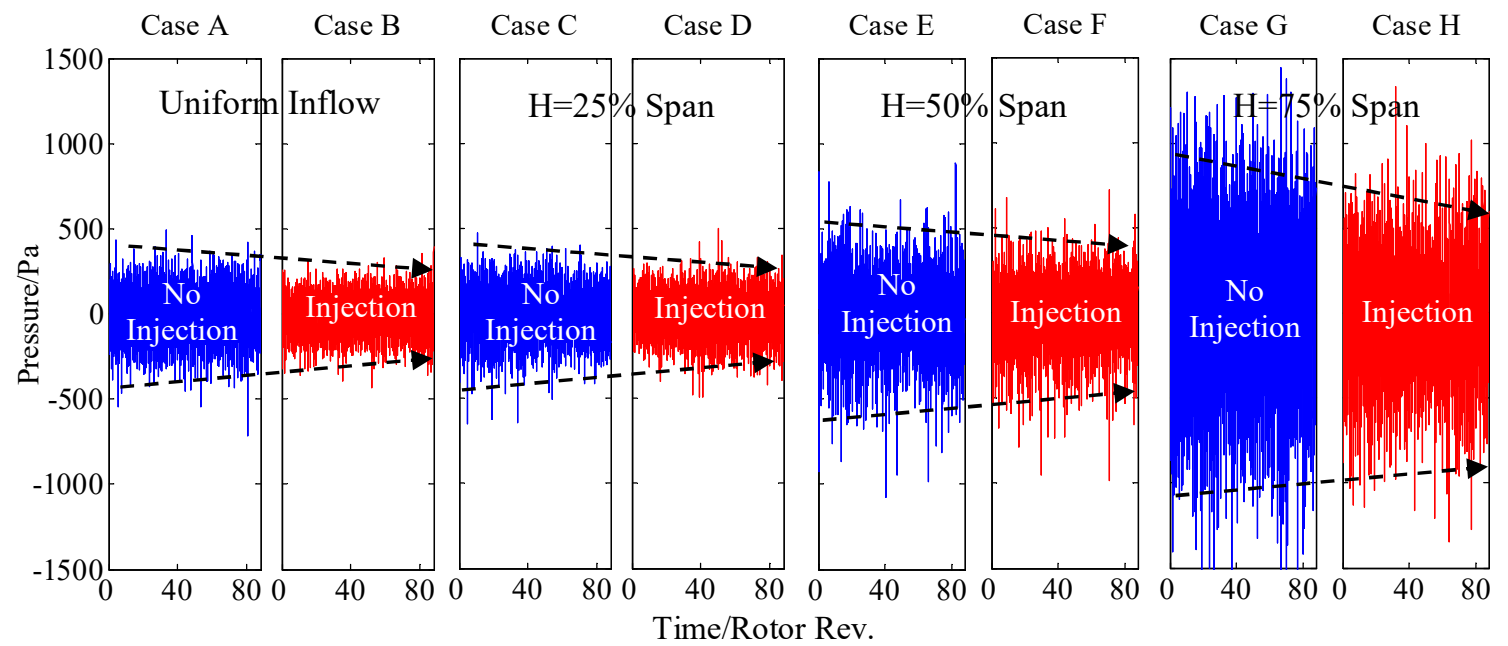

Figure 10 Characteristic Signals at $15.08 \% C_{a x}$ with Steady Injection with Different Distortion

\section{CONCLUSIONS}

In current work, the feasibility of fast wavelet analysis is experimentally investigated to predict the aerodynamic instability subjected to transient circumferential distortion with different distortion intensity in an isolated-rotor axial compressor. There are some conclusions drawn by experimental and analytical results.

The stability suffers from deterioration with inlet circumferential distortion, which is dependent on the distortion intensity. The amplitude of characteristic signal increases or decreases as the generation or disappearance of the inlet circumferential distortion, which means the characteristic signal can timely reflect this adverse effect of transient inlet circumferential distortion on stability.

Steady tip air injection is implemented to improve the stability margin under uniform inflow, circumferential distortion with $0.90 \%, 4.12 \%$ and $24.75 \%$ distortion intensity, respectively. The amplitude of characteristic signal correspondingly decreases in all cases, which depends on the amount of stability enhancement with steady tip air injection.

Therefore, the fast wavelet analysis has a promising application on aerodynamic stability status prediction in axial compressors.

\section{NOMENCLATURE}

$C_{\text {ax }}$

$c_{j k}$

$d_{j k}$

$g_{k}$

$h_{k}$

j

$k$

$P_{\text {s,inlet }}$

$P_{\text {t, inlet }}$

$P_{\text {s,exit }}$

$U_{\text {mid }}$

$V_{x, \text { inlet }}$ axial chord length scaling coefficient wavelet coefficient high pass filter factor low pass filter factor scaling parameter translation parameter inlet static pressure inlet total pressure outlet static pressure tangential velocity at the midspan inlet average velocity

Greek
$\Phi$
$\Psi$
$\psi(x)$
$\phi(x)$
Abbreviations
$B P F$
$L E$
$S M$
$S M V$
$T E$
$T L F$

flow coefficient static-to-total pressure rise coefficient scaling function wavelet function

blade passing frequency

leading edge stall margin stall margin variation trailing edge tip leakage flow

\section{ACKNOWLEDGMENTS}

The authors gratefully acknowledge for the support of the National Natural Science Foundation with Project No. 51727810, No. 51636001, and the National Science and Technology Major Project (2017-II-0004-0017). The authors are also grateful to the Special Fund for the Member of Youth Innovation Promotion Association of CAS (2018173). 


\section{REFERENCES}

[1] Day I. (2015). Stall, Surge and 75 Years of Research. Proceeding of ASME Turbo Expo 2015: Technical Conference and Exposition, GT2015-44109.

[2] Day I. (1991). Stall Inception in Axial Flow Compressors. ASME Journal of Turbomachinery, 115, pp. 1-9.

[3] McDougall N. M., Cumpsty N. A. and Hynes T. P. (1990). Stall Inception in Axial Compressors. ASME Journal of Turbomachinery, 112(1), pp. 116-123.

[4] Tahara N., Kurosaki M., Ohta Y., Outa E. and Shinohara H. (2003). Early Pre-Stall Investigation by Sensitive Stall Warning Technique. Proceeding of the International Gas Turbine Congress, IGTC2003Tokyo TS-044.

[5] Dhingra M., Neumeier Y., Prasad J. V. R., Andrew B. S., Shin H. W. and Szucs P. N. (2006). A Stochastic Model for a Compressor Stability Measure. Journal of Engineering Gas Turbines Power, 129(3), pp. 730-737.

[6] Li J. C. (2017). Self-Adaptive Stability Enhancing Technology with Tip Air Injection in an Axial Flow Compressor. ASME Journal of Turbomachinery, 139(1), pp. 1-9.

[7] Li J. C., Liu Y., Du J. and Zhang H. W. (2020). Automatic Stability Control Using Tip Air Injection in a Multi-Stage Axial Compressor. Aerospace Science and Technology, 98, pp.1-12.

[8] Young A., Day I. and Pullan G. (2012). Stall Warning by Blade Pressure Signature Analysis. ASME Journal of Turbomachinery, 135(1), pp. 1-10.

[9] Li F. Y., Li J., Dong X., Zhou Y. T., Sun D. K. and Sun, X. F. (2016). Stall-Warning Approach Based on Aero-Acoustic Principle. Journal of Propulsion and Power, 32(6), pp. 1-13.

[10] Tryfonidis M., Etchevers O., Paduano J. D., Epstein A. H. and Hendricks G. J. (1995). Prestall Behavior of Several High-Speed Compressors. ASME Journal of Turbomachinery, 117(1), pp. 62-81.

[11] Li J. C., Lin F., Tong Z. T., Nie C. Q. and Chen J. Y. (2015). The Dual Mechanisms and Implementations of Stability Enhancement with Discrete Tip Injection in Axial Flow Compressor. ASME Journal of Turbomachinery, 137(3), pp. 1-10. [12] Du J., Lin F., Zhang H. W. and Chen J. Y. (2010). Numerical Investigation on The Self-Induced Unsteadiness in Tip Leakage Flow for a Transonic Fan Rotor. ASME Journal of Turbomachinery, 132(2), pp. 1-9.

[13] Mailach R., Lehmann I. and Vogeler K. (2001). Rotating Instabilities in an Axial Compressor Originating from the Fluctuating Blade Tip Vortex. ASME Journal of Turbomachinery, 123(3), pp. 453-463.

[14] Liu Y., Li J. C., Du J. Li F. and Zhang H. W. (2019). Application of Fast Wavelet Analysis on Early Stall Warning in Axial Compressors. Journal of thermal science, 28(5), pp. 873-849.

[15] Tahara N., Nakajima T., Kurosaki M. and Nisikawa T. (2001). Active Stall Control with Practicable Stall Prediction System Using Auto-Correlation. 2001 American Institute of Aeronautics \& Astronautics, AIAA Paper No. 2001-3623.

[16] Liu Y., Dhingra M. and Prasad J. V. R. (2010). Active Compressor Stability Management Via a Stall Margin Control Mode. ASME Journal of Turbomachinery, 132, pp. 1-10.

[17] Zhang W. Q. and Vahdati M. (2019). A Parametric Study of the Effects of Inlet Distortion on Fan Aerodynamic Stability. ASME Journal of Turbomachinery, 141, pp. 1-11.

[18] Hah C., Babe D. C., Sullivan T. J. and Wadia A. R. (1998). Effects of Inlet Distortion on the Flow Field in a Transonic Compressor Rotor. ASME Journal of Turbomachinery, 120, pp. 233-246.

[19] Dong X., Sun D. K., Li F. Y. and Sun X. F. (2018). Stall Margin Enhancement of a Novel Casing Treatment Subjected to Circumferential Pressure Distortion. Aerospace Science and Technology, 73, pp.239-255.

[20] Spakovszky Z. S., Schalkwyk C. M. van, Weigl H. J., Paduano J. D., Suder K. L. and Bright M. M. (1999). Rotating Stall Control in a High-Speed Stage with Inlet Distortion: Part II-Circumferential Distortion. ASME Journal of Turbomachinery, 121, pp. 517-524.

[21] Schalkwyk C. M. van, Paduano J. D., Greitzer E. M. and Epstein A. H. (1998). Active Stabilization of Axial Compressors with Circumferential Inlet Distortion. ASME Journal of Turbomachinery, 120, pp. 431-439.

[22] Leinhos D. C., Schmid N. R. and Fottner L. (2001). The Influence of Transient Inlet Distortions on the Instability Inception of a Low-Pressure Compressor in a Turbofan Engine. ASME Journal of Turbomachinery, 123, pp. 1-8.

[23] Longlry J. P., Shin H.-W., Plumley R. E. Silkowski P. D., Day I. J. Greitzer E. M., Tan C. S. and Wisler D. C. (1996). Effects of Rotating Inlet Distortion on Multistage Compressor Stability. ASME Journal of Turbomachinery, 118, pp. 181188.

[24] Dong X., Sun D. K., Li F. Y., Jin D. H., Gui X. M. and Sun X. F. (2015). Effects of Rotating Inlet Distortion on Compressor Stability with Stall Precursor-Suppressed Casing Treatment. ASME Journal of Turbomachinery, 137, pp. 115.

[25] Lin F., Chen J. Y. and Li M. L. (2004). Wavelet Analysis of Rotor-Tip Disturbances in an Axial-Flow Compressor. Journal of Propulsion and Power, 20(2), pp. 319-334.

[26] Liao S. F. and Chen J. Y. (1996). Time-Frequency Analysis of Compressor Rotating Stall by Means of Wavelet Transform. International Gas Turbine and Aeroengine Congress \& Exhibition, 96-GT-57.

[27] Mallat S. (1989). A Theory for Multi-Resolution Signal Decomposition: The Wavelet Representation. IEEE Transaction on Pattern Analysis and Machine Intelligence, 11(7), pp. 674-693.

[28] Mallat S. (1989). Multi-Resolution Approximation and Wavelet Orthonormal Bases of $\mathrm{L}^{2}(\mathrm{R})$. Transaction of the American Math. Society, 315(1), pp. 68-87. 